\title{
Mechanochemically Obtained Phytobiotics Suppress the Development of Pathogens
}

\author{
Igor O. Lomovsky ${ }^{a}$, Vyacheslav Y. Koptev ${ }^{b}$, \\ Marina A. Leonova ${ }^{\mathbf{b}}$ and Oleg I. Lomovsky ${ }^{\text {a* }}$ \\ anstitute of Solid State Chemistry and Mechanochemistry SB RAS \\ Novosibirsk, Russian Federation \\ ${ }^{b}$ Institute of Experimental Veterinary Medicine of Siberia \\ and the Far East of the Scientific Center of Agrobiotechnology RAS \\ Novosibirsk, Russian Federation
}

Received 22.01.2021, received in revised form 15.02.2021, accepted 10.03.2021

\begin{abstract}
A study of the bactericidal action of a number of phytopreparations obtained as a result of mechanochemical treatment of mixtures of plant raw materials with solid sodium carbonate in relation to 10 species of opportunistic bacteria was carried out. The investigated phytopreparations have a selective effect on 1-3 types of microorganisms. The effect of the additive action of phytopreparations in mixtures, which can be used for the prevention and treatment of diseases of animals and humans with an established bacterial etiology, has been discovered.
\end{abstract}

Keywords: mechanochemical treatment, phytopreparations, melanin, biological activity.

Citation: Lomovsky I.O., Koptev V.Y., Leonova M.A., Lomovsky O.I. Mechanochemically obtained phytobiotics suppress the development of pathogens, J. Sib. Fed. Univ. Chem., 2021, 14(1), 91-99. DOI: 10.17516/1998-2836-0219

(C) Siberian Federal University. All rights reserved

This work is licensed under a Creative Commons Attribution-NonCommercial 4.0 International License (CC BY-NC 4.0).

* Corresponding author E-mail address: lomov@solid.nsc.ru 


\title{
Механохимически полученные фитобиотики, подавляющие развитие болезнетворных микроорганизмов
}

\author{
И. О. Ломовский ${ }^{\mathbf{a}}$ В. Ю. Коптев ${ }^{\sigma}$, \\ М. А. Леонова ${ }^{\sigma}$, О.И. Ломовский ${ }^{\mathbf{a}}$ \\ ${ }^{a}$ Институт химии твердого тела и механохимии СО РАН \\ Российская Федерачия, Новосибирск \\ ${ }^{6}$ Институт экспериментальной ветеринарии Сибири \\ и Дальнего Востока Сибирского федерального ичентра \\ агробиотехнологий РАН \\ Российская Федерачия, Новосибирск
}

\begin{abstract}
Аннотация. Проведено исследование бактерицидного действия ряда фитопрепаратов, полученных в результате механохимической обработки смесей растительного сырья с твердым карбонатом натрия в отношении условно-патогенных бактерий Salmonella typhimurium, Shigella sonnei, Esherichia coli, Pasteurella multocida, Yersinia pseudotuberculosis, Streptococcu spyogenes, Staphylococcus aureus, Staphylococcu sepidermidis, Proteus vulgaris, Proteus mirabilis. Исследованные фитопрепараты характеризуются селективным воздействием на один - три вида микроорганизмов. Обнаружен эффект аддитивного действия фитопрепаратов в смеси, который может быть в дальнейшем использован вне смесей для профилактики и терапии конкретных случаев заболевания животных и человека с установленной бактериальной этиологией.
\end{abstract}

Ключевые слова: механохимическая обработка, фитопрепараты, меланин, биологическая активность.

Цитирование: Ломовский, И.О. Механохимически полученные фитобиотики, подавляющие развитие болезнетворных микроорганизмов / И. О. Ломовский, В. Ю. Коптев, М. А. Леонова, О. И. Ломовский // Журн. Сиб. федер. ун-та. Химия, 2021, 14(1). C. 91-99. DOI: 10.17516/1998-2836-0219

\section{Введение}

Интерес к получению фитобиотиков и их использованию в различных отраслях животноводства и пищевой промышленности определяется осознанной обществом необходимостью максимального исключения антибиотиков из кормов и пищи. Под фитобиотиками подразумеваются препараты растительного происхождения, обладающие широким спектром воздействия на микроорганизмы, находящиеся в желудочно-кишечном тракте человека и животных. Наиболее часто упоминаются антимикробные, антивирусные, антигрибковые, иммуностимулирующие, противовоспалительные свойства фитопрепаратов. Фитобиотики повышают продуктивность животных и улучшают качество пищевых продуктов животного происхождения [1].

Несмотря на огромное количество данных о химическом составе растительного сырья, о профилях активности биологически активных соединений, разделение фитобиотиков про- 
водят, например, по следующим признакам: травы, специи, эфирные масла, смолы, экстракты, получаемые с помощью неводных растворителей [2]. Разделение по неоднородным факторам, как и весьма неравномерное распределение информации по активности таких групп фитобиотиков, не обеспечивает понимания принципов создания смесей фитобиотиков. Составы смесей кормовых фитобиотиков, по-видимому, подбирают умозрительно или опытным путем.

В то же время современные механохимические технологии позволяют получать экологически безопасным и экономически эффективным способом порошковые растительные препараты, которые характеризуются повышенной концентрацией растворимых биологически активных веществ [3] и перспективны для пищевой промышленности и кормопроизводства [4].

Получили существенное развитие микробиологические методы анализа микробной заселенности организмов животных и человека, составлены тематические коллекции микроорганизмов, в том числе болезнетворных, характерных для животных и птицы, развиты экспериментальные методы определения влияния биологически активных веществ и препаратов на микроорганизмы.

Цель настоящей работы - определение профиля биологической активности некоторых современных механохимических препаратов, охарактеризованных по содержанию биологических веществ, возможности совмещения препаратов в смесях.

\section{Материалы и методы}

Препараты-фитобиотики готовились путем смешения и механохимической обработки смеси порошков растительного сырья и щелочи, в качестве которой использовался твердый карбонат натрия, обычно в количестве 5 мас.\%. Содержание влаги в растительном сырье составляло 8-10 мас.\%. В качестве механохимического реактора применяли планетарную мельницу-активатор АГО-2 разработки ИХТТМ СО РАН, режим обработки - расчетное ускорение воздействующих тел $200 \mathrm{~m} / \mathrm{c}^{2}$, время обработки 2 мин, воздействующие тела - стальные шары диаметром 5 мм, весовое соотношение обрабатываемая смесь - шаровая загрузка - 1/20.

Виды использованного сырья отобраны в предварительных экспериментах из числа растений, пригодных для пищевого и фармацевтического использования. Критерием отбора было увеличение выхода водорастворимых веществ после механохимической обработки в воде не менее чем на 50 \% по сравнению с необработанным сырьем. Применение карбоната натрия [5] обеспечивало повышение растворимости активных компонентов сырья во всех отобранных случаях.

Исследованы следующие образцы:

1. Зелень пихты $+5 \%$ масс. $\mathrm{Na}_{2} \mathrm{CO}_{3}$.

2. Гречневая лузга, измельченная.

3. Гречневая лузга $+5 \%$ масс. $\mathrm{Na}_{2} \mathrm{CO}_{3}$.

4. Трава рапса $+5 \%$ масс. $\mathrm{Na}_{2} \mathrm{CO}_{3}$.

5. Трава галега $+5 \%$ масс. $\mathrm{Na}_{2} \mathrm{CO}_{3}$.

6. Зеленый чай + рисовая шелуха $+5 \%$ масс. $\mathrm{Na}_{2} \mathrm{CO}_{3}$.

7. Комбинированный препарат $(3+4+5+6)$.

8. Комбинированный препарат $1 / 4(3+4+5+6)$, т. е. препарат 7 с уменьшенным в 4 раза количеством компонентов. 
9. Биосиб-комби, препарат микробного происхождения, образец сравнения, производство «СИББИОФАРМ», г. Бердск Новосибирской области.

Определение общего количества растворимых веществ проводилось методом исчерпывающей экстракции в аппарате Сокслета водой, выпариванием и взвешиванием экстракта. Содержание наиболее активных, по литературным данным, веществ определялось для каждого исследуемого случая по известным методикам.

Зелень хвойных является одним из наиболее популярных фитобиотиков, используемым в течение длительного времени [6]. При механохимическом взаимодействии с карбонатом натрия получен препарат (1) (табл. 1), содержащий до 33 \% растворимых веществ, доля активных тритерпеновых кислот в котором составила $1,2 \%$ [7].

Гречневая лузга привлекает внимание как доступный источник меланинов - активных полифенольных веществ, в механохимических экстрактах (3), полученных с карбонатом натрия, их доля составляет до $15 \%$ [8]. Препарат из измельченной гречневой лузги (2) включен для иллюстрации, насколько механохимическая активация увеличивает эффективность выделения меланинов. Анализ меланинов проводился по методике [9], отработанной для меланинов древесных грибов.

Трава рапса представляется в настоящее время перспективным источником кверцетина и его производных - относительно низкомолекулярных полифенолов, обладающих выраженным антиоксидантным действием (4) [10], содержание в исходном сырье составляет 0,38 \%. Трава галега (галега восточная), введенная в культуру в качестве источника кормового белка, обладает перспективами применения в фармакологии, прежде всего по причине высокого содержания в ней растительных аналогов метформина [18] и карбоциклических сахаров (5).

Таблица 1. Общее содержание водорастворимых веществ и содержание действующих веществ в исследованных препаратах

Table 1. The content of water - soluble substances and the content of substances in the studied preparations

\begin{tabular}{|c|c|c|c|c|c|}
\hline № & Образец, название & $\begin{array}{c}\text { Общее } \\
\text { содержание } \\
\text { водорастворимых } \\
\text { веществ, \% масс. }\end{array}$ & $\begin{array}{c}\text { Действующие } \\
\text { вещества }\end{array}$ & $\begin{array}{c}\text { Содержание, } \\
\text { \% масс. }\end{array}$ & $\begin{array}{c}\text { Методика } \\
\text { определения } \\
\text { действующих } \\
\text { веществ, ссылки }\end{array}$ \\
\hline 1 & $\begin{array}{l}\text { Зелень пихты + } 5 \text { \% } \\
\text { масс. } \mathrm{Na}_{2} \mathrm{CO}_{3}\end{array}$ & 33 & $\begin{array}{c}\text { Тритерпен. } \\
\text { кислоты }\end{array}$ & 1,2 & 7 \\
\hline 2 & Гречневая лузга & 5 & Меланины & 0,8 & 9 \\
\hline 3 & $\begin{array}{l}\text { Гречневая лузга }+5 \% \\
\text { масс. } \mathrm{Na}_{2} \mathrm{CO}_{3}\end{array}$ & 14 & Меланины & 4,5 & 9 \\
\hline 4 & $\begin{array}{l}\text { Трава рапса }+5 \% \text { масс. } \\
\mathrm{Na}_{2} \mathrm{CO}_{3}\end{array}$ & 30 & $\begin{array}{c}\text { Сумма } \\
\text { флавоноидов } \\
\text { (кверцетин) }\end{array}$ & 0,38 & 17 \\
\hline 5 & $\begin{array}{l}\text { Трава галега + } 5 \text { \% масс. } \\
\mathrm{Na}_{2} \mathrm{CO}_{3}\end{array}$ & 34 & Галегин & 0,2 & 11 \\
\hline \multirow[t]{2}{*}{6} & \multirow{2}{*}{$\begin{array}{l}\text { Зеленый чай + рисовая } \\
\text { шелуха }+5 \% \text { масс. } \\
\mathrm{Na}_{2} \mathrm{CO}_{3}\end{array}$} & 30 & $\begin{array}{c}\text { Катехины } \\
\text { зеленого чая }\end{array}$ & 1,6 & 19 \\
\hline & & 30 & Хелат кремния & 0,002 & 13 \\
\hline
\end{tabular}


Препарат «зеленый чай + рисовая шелуха» (6) привлекает внимание содержанием продуктов механохимического взаимодействия и низкомолекулярных полифенолов и аморфного диоксида кремния рисовой шелухи [12] - хелатных комплексов диоксида кремния и галлокатехинов чая, обладающих антибактериальным [13] и антивирусными свойствами [14]. Комбинированный препарат (7) представляет собой смесь указанных в табл. 1 фитобиотиков. В комбинированном препарате (8) содержание фитобиотиков в 4 раза меньше, чем в препарате (7). Препарат сравнения (9) предоставлен ПО «СИББИОФАРМ», г. Бердск Новосибирской области.

При проведении исследований антагонистической активности образцов руководствовались методиками, изложенными в ОФС.1.7.2.0012.15 «Производственные пробиотические штаммы и штаммы для контроля пробиотиков», ОФС.1.7.2.0001.15 «Безопасность пробиотиков в опытах in vivo» [15] и МУК 4.2.1890-04 «Определение чувствительности микроорганизмов к антибактериальным препаратам» [16]. Метод основан на прямом определении основного количественного показателя - минимальной концентрации, подавляющей видимый рост исследуемого микроорганизма в бульонной культуре или на плотной среде. Заданные концентрации антибактериального препарата вносят в питательную среду, которую затем засевают культурой исследуемого микроорганизма и после инкубации оценивают наличие или отсутствие видимого роста.

В качестве тест-культур применяли музейные штаммы и полевые изоляты следующих микроорганизмов: Salmonella typhimurium, Shigella sonnei, Esherichia coli, Pasteurella multocida, Yersinia pseudotuberculosis, Streptococcus pyogenes, Staphylococcus aureus, Staphylococcus epidermidis, Proteus vulgaris, Proteusmirabilis.

При работе с микроорганизмами использовали мясопептонный агар (МПА) производства ФБУН «Государственный научный центр прикладной микробиологии и биотехнологии» (г. Оболенск).

\section{Обсуждение результатов}

Результаты определения чувствительности микроорганизмов к антибактериальным препаратам - антагонистической активности представленных образцов приведены в табл. 2.

Положительные результаты сводятся к следующим:

- препарат (1) из зелени пихты активен в отношении Salmonella typhimurium, Shigella sonnei, Pasteurella multocida, Yersinia pseudotuberculosis, Staphylococcus epidermidis;

- препарат (3) из гречневой лузги - в отношении Salmonella typhimurium, Esherichia coli, Staphylococcus aureus;

- препарат (4) из травы рапса - Salmonella typhimurium, Shigella sonnei;

- препарат (5) из травы галеги - Proteus vulgaris;

- препарат (6) из зеленого чая и рисовой шелухи - Pasteurella multocida.

Сравнение активности образцов растительного происхождения (1) - (8) с активностью комбинированного образца, полученного микробиологическим синтезом (9), показывает, что фитопрепараты обладают высокой селективностью действия. Исследованные образцы (3) - (6) фитобиотиков активны по отношению к одному - трем видам микроорганизмов из исследованных десяти. 
Таблица 2. Антагонистическая активность образцов фитобиотиков

Table 2. Antagonistic activity of the phytobiotic samples

\begin{tabular}{|c|c|c|c|c|c|c|c|c|c|c|c|}
\hline № & Штамм & 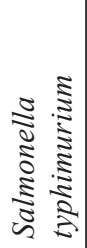 & 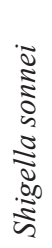 & 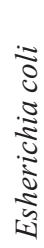 & 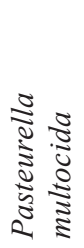 & 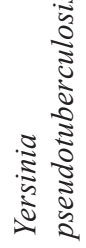 & 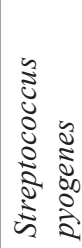 & 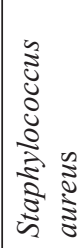 & 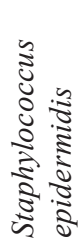 & 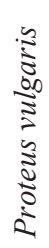 & 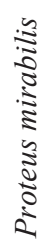 \\
\hline 1 & Зелень пихты $+5 \% \mathrm{Na}_{2} \mathrm{CO}_{3}$ & + & + & - & + & - & - & + & + & - & - \\
\hline 2 & Гречневая лузга & - & - & - & - & - & - & - & - & - & - \\
\hline 3 & Гречневая лузга +5 \% $\mathrm{Na}_{2} \mathrm{CO}_{3}$ & + & - & + & - & - & - & + & - & - & - \\
\hline 4 & Трава рапса $+5 \% \mathrm{Na}_{2} \mathrm{CO}_{3}$ & + & + & - & - & - & - & - & - & - & - \\
\hline 5 & Галега $+5 \% \mathrm{Na}_{2} \mathrm{CO}_{3}$ & - & - & - & - & - & - & - & - & + & - \\
\hline 6 & $\begin{array}{l}\text { Зеленый чай + рисовая шелуха } \\
+5 \% \mathrm{Na}_{2} \mathrm{CO}_{3}\end{array}$ & - & - & - & + & - & - & - & - & - & - \\
\hline 7 & $\begin{array}{l}\text { Комбинированный препарат } \\
(3+4+5+6)\end{array}$ & + & + & - & - & - & - & + & - & - & - \\
\hline 8 & $\begin{array}{l}\text { Комбинированный препарат } \\
1 / 4(3+4+5+6+7)\end{array}$ & + & - & - & - & - & - & + & - & - & - \\
\hline 9 & Биосиб-комби & - & + & + & + & + & + & + & + & - & - \\
\hline
\end{tabular}

Примечания:

- $\quad(+)$ - выраженный антагонизм; (-) - отсутствие антагонизма;

- $\quad$ водный раствор $\mathrm{Na}_{2} \mathrm{CO}_{3}$ в концентрации, вводимой с фитопрепаратами, активностью не обладает.

Образец (1) из зелени пихты подавляет развитие пяти видов микроорганизмов. Более широкий спектр подавляемых микроорганизмов может объясняться более сложным составом активных веществ в препарате, в частности, кроме активных тритерпеновых кислот в зелени хвойных присутствуют ароматические масла [1]. Среднее содержание масел в зелени пихты более $5 \%$, из них $30 \%$ - борнилацетат.

Образец (7) представляет собой комбинированный из равных количеств образцов (3), (4), (5) и (6) фитопрепарат. Видно, что набор подавляемых им микроорганизмов - это обедненный суммарный список микроорганизмов, на которые воздействует каждый индивидуальный фитопрепарат, входящий в состав комбинированного фитопрепарата. Возможной причиной сокращения списка микроорганизмов является взаимодействие компонентов различного сырья между собой и превращение действующих веществ в неактивные химические формы.

Обнаруженный эффект аддитивного действия фитопрепаратов в смеси может быть в дальнейшем использован для обоснованного подхода к составлению комбинированных препаратов, который нужно использовать в конкретных случаях профилактики и терапии человека и животных. В последующем при расширении сведений о селективности воздействия фитопрепаратов и состава болезнетворных микроорганизмов, характерных для конкретного случая заболевания, может осуществляться подбор смесей фитопрепаратов для каждого заболевания.

Сравнение образцов (2) и (3) демонстрирует, что эффективность фитопрепаратов, полученных механохимической обработкой растительного сырья со специальным реагентом, выше

$$
\text { - } 96-
$$


эффективности измельченного в тех же условиях растительного сырья. По-видимому, данный эффект определяется образованием в ходе обработки растворимых, в данном случае солевых, форм биологически активных веществ и повышением их экстрагируемости.

Сравнение образцов (7) и (8), отличающихся уменьшенным в 4 раза содержанием компонентов смеси, показывает, что такое снижение также приводит к уменьшению спектра подавляемых микроорганизмов, по-видимому, за счет понижения концентрации отдельных активных веществ ниже порога чувствительности.

\section{Выводы}

1. Из растительного сырья механохимической обработкой с твердой щелочью могут быть получены порошковые препараты, обладающие повышенной антибактериальной активностью по сравнению с исходным сырьем.

2. Исследованные фитопрепараты характеризуются селективным воздействием на один три вида условно-патогенных микроорганизмов из исследованных десяти.

3. Препараты с активностью против определенных видов микроорганизмов могут получаться смешением фитопрепаратов из подходящих типов сырья.

4. Обнаруженный эффект аддитивного действия фитопрепаратов в смеси может быть в дальнейшем использован для составления смесей, которые нужно применять в конкретных случаях заболевания животных, для которых известны типы микроорганизмов, вызывающих заболевания.

\section{Благодарности / Acknowledgments}

Работа поддержана Российским научным фондом (проект № 16-13-10200).

Работа выполнена в рамках государственного задания ИХТТМ СО РАН (проект № AAAA-A17-117030310279-0).

This study was supported by the Russian Science Foundation (project No. 16-13-10200).

The research was funded within the state assignment to ISSCM SB RAS (project № AAAA-A17-117030310279-0).

\section{Список литературы / References}

1. Gheisar M.M., Kim I.H. Phytobiotics in poultry and swine nutrition- a review 2018. Vol. 17(1), P. 92-99.

2. Багно О.А., Прохоров О.Н., Шевченко С. А., Шевченко А. И., Дядичкина Т. В. Фитобиотики в кормлении сельскохозяйственных животных 2018. Т. 53(4), С. 687-697. [Bagno О.А., Prokhorov O.N, Shevchenko S. A., Shevchenko A. I., Dyadichkina T. V. Use of phytobioticsin pharm animal feeding. 2018. Vol. 53(4), P. 687-697. (in Russ.)]

3. Lomovsky O.I., Lomovsky I.O. Mechanochemicaly assisted extraction in Enhancing Extraction Processes in the Food Industry. Ed. By N. Lebovka, E. Vorobiev, F. Chemat, NY - London: CRC Press 2012. Pp. 361-398.

4. Ломовский И.О., Ломовский О.И. Механохимический гидролиз биополимеров в технологиях пищевой промышленности и кормопроизводства. Обзор. Химия в интересах устойчивого развития 2019. Т. 27(3). C. 257-266. [Lomovsky I. O., Lomovsky O.I. Mechanochemical 
hydrolysis of biopolymers in technologies of the food industry and feed production. Review. Chemistry in Sustainable Development 2019. Vol. 27(3). P. 257-266 (in Russ.)]

5. Lomovsky O.I., Lomovsky I.O., Orlov D. V. Mechanochemical solid acid/base reactions for obtaining biological active preparations and extracting plant materials. Green Chemistry Letters and Reviews 2017. Vol. 10(4), Р. 171-185.

6. Табаков Н.А., Козина Е. А., Ки-Ю-Ан Н.А., Рябинина Л. А. Биологически активные добавки растительного происхождения в кормлении животных и птиц. Кормление сельскохозяйственных животных и кормопроизводство 2008. T. 6, С. 50-55. [Tabakov N. A., Kozina E. A., Ki-Yu-An N.A., Ryabinina L. A. Biologically active additives of plant origin in animal and bird feeding. Feeding farm animals and forage production 2008. Vol. 6, P. 50-55 (in Russ.)].

7. Korolev K.G., Lomovskii O.I., Rozhanskaya O.A., Vasil'ev V.G. Mechanochemical preparation of water-soluble forms of triterpene acids. Chemistry of Natural Compounds 2003. Vol. 39(4), С. 366-372.

8. Мацейчик И.В., Корпачева С.М., Ломовский И.О., Серасутдинова К.Р. Перспективы использования продуктов переработки гречихи в качестве функциональных ингредиентов. Продукты функционального и специализированного назначения 2020. Т. 2(61), С. 53-57. [Matseychik I. V., Korpacheva S. M., Lomovsky I.O., Serasutdinova K.R. Prospects for the use of products of buck wheat as functional ingredients 2020. Vol. 2(61), P. 53-57 (in Russ.)]

9. Lomovsky O.I., Lomovsky I.O., Teplyakova N.V. The concentration of melan in powder materials obtained from white-rot fungi by mechanochemical method. IOP Conf. Series: Materials Science and Engineering 2019. V. 479. № 1. 012010.

10. Съедин А.В. Фармакогностическое изучение рапса обыкновенного: автореф. дис. ... канд. фарм. наук: 14.04.02. Пятигорск., 2014. 24 с. [Sedin A. V. Pharmacognostic study of conventionalrape: Authoref. dis. ... cand. Pharm. Sciences: 04.14.02. Pyatigorsk., 2014. 24 c. (in Russ.)] http://medical-diss.com/medicina/farmakognosticheskoe-izuchenie-rapsa-obyknovennogo\#ixzz6XVk0ZWGd

11. Pankrushina N.A., Salnikova O. I., Lomovsky O. I. Chemical constituent of Galegaorientalis produced by mechanochemical procedure. Fundamental Bases of Mechanochemical Technologies. The Book of Abstracts of the V Intern. Conf. 25-28 June 2018, Novosibirsk, Russia. Novosibirsk: IPC NSU, 2018. 234 p., P. 69.

12. Trofimova E.G., Lomovsky O.I. The mechanism of mechanochemicalinteraction betweenamorphous silicon dioxide and pyrocatechol. Silicon 2020. P. 1-7.doi.org/10.1007/s12633020-00444-y.

13. Shapolova E.G., Lomovskii O.I. Features of the mechanical treatment of rice husk for the performance of the solid-phase reaction of silicon dioxide with polyphenols. Russian Journal of Bioorganic Chemistry 2016. Vol. 42(7). P. 93-98.

14. Shapolova E.G., Lomovskii O. I., Kazachinskaya E. I., Loktev V. B., Teplyakova T. V. Antiviral activity of $\mathrm{SIO}_{2}-$ polyphenol composites prepared mechanochemically from plant raw materials. Pharmaceutical Chemistry Journal 2016. Vol. 50(9), C. 595-599.

15. Общая фармакопейная статья 1.7.2.0012.15 «Производственные пробиотические штаммы и штаммы для контроля пробиотиков» [Manufactured probiotic strains and probiotic control strains (in Russ.)] http://resource.rucml.ru/feml/pharmacopia/14_1/HTML/index.html. 
16. Методические указания 4.2.1890-04 Определение чувствительности микроорганизмов к антибактериальным препаратам. Федеральный центр Госсанэпиднадзора Минздрава России 2004. C. 91. [Determination of the sensitivity of microorganisms to antibacterial drugs. Federal center for State Sanitary and Epidemiological Supervision of the Ministry of Health of Russia 2004. P. 91. (in Russ.)]

17. Лобанова А.А., Будаева В.В., Сакович Г. В. Исследование биологически активных флавоноидовв экстрактах из растительного сырья. Химия растительного сырья 2004. Т. 1, С. 47-52. [Lobanova A. A., Budaeva V. V., Sakovich G. V. Research of biologically active flavonoids in extracts from plant raw materials. Chemistry of Plant Materials 2004. Vol. 1, P. 47-52. (in Russ.)]

18. Raigond P., Kaundal B., Sood A., Shikha D., Som D., Brajesh S. Quantification of biguanide and related compounds (anti-diabetic) invegetables and fruits. Journal of Food Composition and Analysis 2018. Vol. 74, P. 82-88.

19. Lomovsky I.O. Stability of green tea catechins in the solid phase and aqueous solutions. Chemistry for Sustainable Development 2012. Vol. 20(2), P. 215-220. 